\title{
Early estimates of the effectiveness of the 2011/12 influenza vaccine in the population targeted for vaccination in Spain, 25 December 2011 to 19 February 2012
}

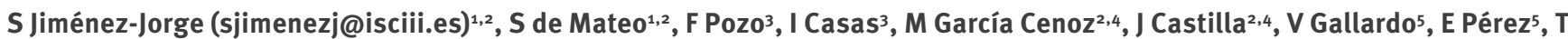
Vega $^{6}$, C Rodriguez ${ }^{6}$, C Quinones ${ }^{7}$, E Martínez ${ }^{7}$, J Giménez ${ }^{8}$, J M Vanrell ${ }^{8}$, D Castrillejo ${ }^{9}$, M C Serrano ${ }^{10}$, J M Ramos ${ }^{10}$, A Larrauri, $^{1,2}$

1. National Centre of Epidemiology, Institute of Health Carlos III, Madrid, Spain

2. Ciber Epidemiología y Salud Pública (CIBERESP), Ministry of Economy and Competitiveness, Institute of Health Carlos III, Madrid, Spain

3. National Centre for Microbiology, World Health Organization National Influenza Centre, Institute of Health Carlos III, Madrid, Spain

4. Instituto de Salud Pública de Navarra, Navarra, Spain

5. Servicio de Epidemiología y Salud Laboral. Secretaría General de Salud Pública y Participación. Consejería de Salud de Andalucía, Seville, Spain

6. Dirección General de Salud Pública, Consejería de Sanidad de Castilla y León, Valladolid, Spain

7. Servicio de Epidemiología, Subdirección de Salud Pública de La Rioja, La Rioja, Spain

8. Servicio de Epidemiología, Dirección General de Salut Pública, Mallorca, Baleares, Spain

9. Servicio de Epidemiología, Dirección General de Sanidad y Consumo, Consejería de Bienestar Social y Sanidad, Ciudad Autónoma de Melilla, Spain

10. Dirección General de Salud Pública, Servicio Extremeño de Salud, Badajoz, Junta de Extremadura, Spain

Citation style for this article:

Jiménez-Jorge S, de Mateo S, Pozo F, Casas I, García Cenoz M, Castilla J, Gallardo V, Pérez E, Vega T, Rodriguez C, Quinones C, Martínez E, Giménez J, Vanrell JM, Castrillejo D, Serrano MC, Ramos JM, Larrauri A. Early estimates of the effectiveness of the 2011/12 influenza vaccine in the population targeted for vaccination in Spain, 25 December 2011 to 19 February 2012

Euro Surveill. 2012;17(12):pii=20129. Available online: http://www.eurosurveillance.org/ViewArticle.aspx?Articleld=20129

Article published on 22 March 2012

We present early estimates of influenza vaccine effectiveness (VE) in the population targeted for vaccination, during 25 December 2011 to 19 February 2012. The adjusted VE was $55 \%(95 \% \mathrm{Cl}: 3$ to 79$)$ against any type of influenza virus and $54 \%(95 \% \mathrm{Cl}: 1$ to 79$)$ against influenza $\mathrm{A}\left(\mathrm{H}_{3} \mathrm{~N}_{2}\right)$ virus. This suggests a moderate protective effect of the vaccine in the targeted population in a late influenza epidemic with limited match between vaccine and circulating strains.

\section{Background}

The effectiveness of the trivalent seasonal and pandemic influenza vaccines has been estimated in Spain since the 2008/09 season using the observational testnegative case-control cycEVA study, the Spanish component of the European Centre of Disease Prevention and Control (ECDC)-funded project, I-MOVE (Monitoring Vaccine Effectiveness in Europe) [1].

The 2011/12 influenza seasonal trivalent vaccine composition recommended for the northern hemisphere included the same strains as in the previous season: the influenza $A\left(\mathrm{H}_{1} \mathrm{~N}_{1}\right)_{2009}$ pandemic strain $A / C a l i f o r n i a / 07 / 2009$, in addition to the $\mathrm{A}\left(\mathrm{H}_{3} \mathrm{~N}_{2}\right)$ (A/Perth/16/2009-like) and $B$ strains (B/ Brisbane/60/2008-like) strains [2].
In Spain, the target groups for influenza vaccination this season were individuals over six months old with major chronic conditions or with risk factors such as pregnancy or morbid obesity, the elderly over 59 years old (over 64 years old in some regions), healthcare workers and caregivers [3].

The cycEVA study was able to provide intraseasonal influenza vaccine effectiveness (VE) estimates in the previous 2010/11 season [4]. Here we present early estimates of the effectiveness of the 2011/12 seasonal trivalent influenza vaccine in preventing medically attended laboratory-confirmed influenza infections in the population targeted for vaccination, during the time when the epidemic in Spain was increasing (25 December 2011 to 19 February 2012), eight weeks after its start.

\section{Methods}

In the current influenza season, seven regional networks belonging to the Spanish Influenza Sentinel Surveillance System, distributed throughout Spain, participated in the cycEVA study. We used similar methods to those carried out in the previous three seasons in the cycEVA study [4-7]. Briefly, the 231 participating sentinel general practitioners (GPs) and paediatricians systematically swabbed the first two patients each week aged under 65 years consulting for influenza-like 
illness (ILI) and all patients aged 65 years and over consulting for ILI, from week 52 (25 December) 2011 to week 7 (19 February) 2012.

ILI patients were recruited according to a case definition based on that of the European Commission: sudden onset of symptoms and at least one of these four systemic symptoms (fever or feverishness, malaise, headache, myalgia), and at least one of these three respiratory symptoms (cough, sore throat, shortness of breath), in the absence of another possible differential clinical diagnosis [8]. Influenza cases were laboratory confirmed for the presence of influenza viruses by genome amplification methods reverse transcriptionPCR and/or cell culture using a Madin-Darby canine kidney (MDCK) cell line. Controls were ILI patients who tested negative for any type of influenza virus.

We considered a patient vaccinated if they had received the 2011/12 influenza vaccine at least 14 days before the ILI symptom onset.

The variables assessed during this season were the same as in 2010/11 [7], except for pandemic vaccination status and functional status (the need for assistance in walking or bathing), which were not assessed this season.

The National Centre of Microbiology (World Health Organization National Influenza Centre-Madrid) selected a subset of influenza isolates in order to get a homogeneous distribution by age group, geographical origin and epidemiological week. The isolates were genetically characterised by sequencing the $\mathrm{HA}_{1}$ fragment of the viral haemagglutinin gene. Phylogenetic analysis of sequences was carried out in order to characterise the specific strains of influenza $A$ and $B$ viruses.

We estimated the influenza VE against any type of influenza virus and against $A\left(\mathrm{H}_{3} \mathrm{~N}_{2}\right)$ influenza virus (the predominant influenza subtype virus in Spain since the beginning of the 2011/12 season) in the target groups for vaccination, restricting the analysis to ILI patients swabbed less than eight days after onset of symptoms in order to reduce the chance of misclassification due to false-negative results over time.

We used a logistic regression model to calculate adjusted influenza VE, including in the model those variables that changed the crude odds ratio by more than $10 \%$ and met the two necessary criteria for confounding, i.e. to be a risk factor for the laboratory-confirmed influenza infection in non-vaccinated patients and to be associated with the influenza 2011/12 vaccination [9].

\section{Results}

ILI rate and influenza virus type in

the 2011/12 influenza season

The ILI rate exceeded the epidemic threshold (53.43

ILI cases per 100,000 population) in week 52 (25-31 December) 2011 in Spain. The epidemic wave reached its peak in week 7 (13-19 February) 2012 at both the national level and in the seven regions participating in the cycEVA study [10]. The highest incidence was recorded in the age group 0-4 years, with a maximum weekly incidence of $656 \mathrm{ILI}$ cases per 100,000 population.

Since the beginning of the 2011/12 season, influenza $A\left(\mathrm{H}_{3} \mathrm{~N}_{2}\right)$ virus has been the predominant circulating subtype of influenza A virus in Spain: $90 \%$ of influenza $A$ viruses were subtyped, $99 \%$ of those subtyped were influenza $A\left(\mathrm{H}_{3} \mathrm{~N}_{2}\right)$. The maximum percentage of influenza-positive samples was $69 \%$, during the peak.

\section{Participants' characteristics}

Among the $231 \mathrm{GPs}$ and paediatricians who agreed to participate in the study, $179(77 \%)$ recruited at least one ILI patient. Of the 935 ILI patients recruited, 204 $(22 \%)$ were in the vaccination target groups. After excluding four patients with unknown laboratory results and three swabbed more than eight days after symptom onset, $197 \mathrm{ILI}$ patients were included in the study. These comprised 128 influenza cases (121 with influenza $A\left(\mathrm{H}_{3} \mathrm{~N}_{2}\right)$ virus, one with influenza $A\left(\mathrm{H}_{1} \mathrm{~N}_{1}\right)$ pdmog virus, three in whom the influenza $A$ virus was not subtyped and three with influenza B virus) and 69

\section{FIGURE}

Recruited influenza cases $(\mathrm{n}=128)$ and test-negative controls $(n=69)$ targeted for vaccination and ILI incidence in sentinel regions, cycEVA study, Spain, week 40 (2-8 October) 2011-week 7 (13-19 February) 2012

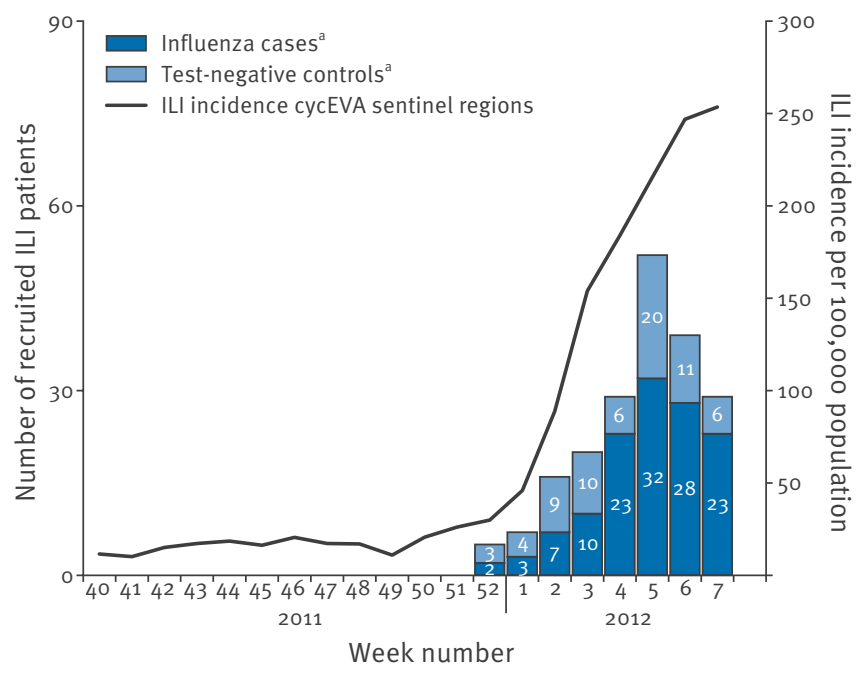

ILI: influenza-like illness.

a Cases and controls recruited during week 52 (25-31 December) 2011 to week 7 (13-19 February) 2012 and with an interval between ILI symptom onset and swabbing of less than eight days. 
test-negative controls. The weekly distribution of the recruited ILI patients followed the ILI incidence in the seven participating networks (Figure) as well as at the national level [10].

The characteristics of the recruited influenza cases did not differ from the test-negative controls in any of the variables assessed (Table 1). Although cases were older than controls (a median age of 60 years versus 49 years), this difference was not statistically significant $(p=0.150)$. The median number of visits per patient to a $\mathrm{GP}$ or and paediatrician in the previous year was five in the cases and four in the controls $(p=0.487)$. The percentage vaccinated was similar in the $2011 / 12$ and the $2010 / 11$ seasons in the cases $(26 \%$ and $20 \%$, respectively) and in the controls (33\% and $32 \%$, respectively).

\section{TABLE 1}

Characteristics of recruited influenza cases $(n=128)$ and test-negative controls $(n=69)$ targeted for vaccination, cycEVA study, Spain, week 52 (25-31 December) 2011-week 7 (13-19 February) 2012

\begin{tabular}{|c|c|c|c|}
\hline Variable & Influenza cases ${ }^{a}$ & Test-negative controls ${ }^{a}$ & P value \\
\hline Median age in years (range) & $60.5(3-82)$ & $49(3-86)$ & $0.150^{\mathrm{b}}$ \\
\hline \multicolumn{4}{|l|}{ Age group in years - number/total number (\%) } \\
\hline $0-4$ & $3 / 128(2)$ & $3 / 69(4)$ & \multirow{4}{*}{$0.488^{c}$} \\
\hline $5-14$ & $11 / 128(9)$ & $4 / 69(6)$ & \\
\hline $15-64$ & $67 / 128(52)$ & $42 / 69(61)$ & \\
\hline$\geq 65$ & 47/128 (37) & $20 / 69(29)$ & \\
\hline Sex: male - number/total number (\%) & $59 / 128(46)$ & $32 / 69(46)$ & $0.970^{c}$ \\
\hline Any chronic condition reported & $69 / 127(54)$ & $44 / 69(64)$ & $0.202^{c}$ \\
\hline Pregnancy & $5 / 128(4)$ & $1 / 69(1)$ & $0.338^{c}$ \\
\hline Morbid obesity $^{d}$ & $7 / 127(6)$ & $5 / 69(7)$ & $0.629^{c}$ \\
\hline Any hospitalisation for chronic conditions in previous year & 4/127(3) & $0 / 69(0)$ & $0.136^{c}$ \\
\hline \multicolumn{4}{|l|}{ Visits to a GP or paediatrician in previous year } \\
\hline Median number of visits per patient (range) & $5(0-20)$ & $4(0-32)$ & $0.487^{\mathrm{b}}$ \\
\hline Number that did not visit & $15 / 127(12)$ & $7 / 68(10)$ & \multirow{2}{*}{$0.750^{\mathrm{c}}$} \\
\hline Number that visited at least once & $112 / 127(88)$ & $61 / 68(90)$ & \\
\hline Smoker & $20 / 125(16)$ & $16 / 68(23)$ & $0.200^{c}$ \\
\hline Interval between symptom onset and swabbing less 4 days & $123 / 128(96)$ & $66 / 69(96)$ & $0.881^{c}$ \\
\hline \multicolumn{4}{|l|}{ Vaccination status- number/total number (\%) } \\
\hline Received seasonal 2011/12 vaccine ${ }^{e}$ & $33 / 128(26)$ & $23 / 69(33)$ & $0.262^{c}$ \\
\hline Received seasonal 2010/11 vaccine & $26 / 127(20)$ & $22 / 69(32)$ & $0.076^{c}$ \\
\hline
\end{tabular}

GP: general practitioner; ILI: influenza-like illness.

a Cases and controls recruited during the specified time period (week 52 (25-31 December) 2011 to week 7 (13-19 February) 2012) and with an interval between ILI symptom onset and swabbing of less than eight days.

b Non-parametric test of the median.

c Chi-square test or Fisher's exact test, when appropriate.

d Defined as body mass index greater than $40 \mathrm{~kg} / \mathrm{m}^{2}$.

e Vaccination at least 14 days before the onset of ILI symptoms.

\section{TABLE 2}

Effectiveness of trivalent 2011/12 influenza vaccine against any type of influenza virus and influenza A(H3N2) virus in recruited influenza cases $(n=128)$ and test-negative controls $(n=69)$ targeted for vaccination, cycEVA study, Spain, week 52 (25-31 December) 2011-week 7 (13-19 February) 2012

\begin{tabular}{|c|c|c|c|c|c|c|}
\hline $\begin{array}{l}\text { Type/subtype of influenza } \\
\text { virus }\end{array}$ & $\begin{array}{c}\text { Number of } \\
\text { influenza cases } \\
\text { a }\end{array}$ & $\begin{array}{c}\text { Number of test- } \\
\text { negative controls }\end{array}$ & $\begin{array}{c}\text { Number of vaccinated } \\
\text { influenza cases }\end{array}$ & $\begin{array}{l}\text { Number of vaccinated } \\
\text { test-negative controls }\end{array}$ & \multicolumn{2}{|c|}{$\begin{array}{c}\text { Vaccine effectiveness } \\
\%(95 \% \mathrm{Cl})\end{array}$} \\
\hline \multirow{2}{*}{ Any type of influenza virus } & \multirow{2}{*}{128} & \multirow{2}{*}{69} & \multirow{2}{*}{33} & \multirow{2}{*}{23} & Crude & $31(-39$ to 65$)$ \\
\hline & & & & & Adjusted $^{b}$ & $55(3$ to 79$)$ \\
\hline \multirow{2}{*}{ Influenza $\mathrm{A}\left(\mathrm{H}_{3} \mathrm{~N}_{2}\right)$ virus } & \multirow{2}{*}{121} & \multirow{2}{*}{69} & \multirow{2}{*}{32} & \multirow{2}{*}{23} & Crude & $28(-45$ to 64$)$ \\
\hline & & & & & Adjusted $^{\mathrm{b}}$ & 54 (1 to 79$)$ \\
\hline
\end{tabular}

ILI: influenza-like illness.

a Cases and controls recruited during the specified time period (week 52 (25-31 December) 2011 to week 7 (13-19 February) 2012 and with an interval between ILI symptom onset and swabbing of less than eight days.

b Model adjusted for age groups, smoking history and week of swabbing. 
During the study period, 33 vaccine failures were notified: 32 were in cases with laboratory-confirmed influenza $\mathrm{A}\left(\mathrm{H}_{3} \mathrm{~N}_{2}\right)$ virus and one was in a case with laboratory-confirmed influenza $B$ virus. Of all the vaccine failures, 11 were cases who were older than 64 years and had at least one chronic condition.

\section{Vaccine effectiveness estimates}

The crude influenza VE against any type of influenza virus was $31 \%$ (95\% Cl: -39 to 65 ). The adjusted VE, adjusted for age groups, smoking history and week of swabbing, was $55 \%(95 \% \mathrm{Cl}: 3$ to 79 ) (Table 2). Similar estimates were obtained when effectiveness of the vaccine against influenza $\mathrm{A}\left(\mathrm{H}_{3} \mathrm{~N}_{2}\right)$ virus was assessed, with adjusted VE estimates of $54 \%$ ( $95 \% \mathrm{Cl}: 1$ to 79 ).

Although the number of visits to GPs or paediatricians and hospitalisation for chronic conditions in the previous year were not identified as confounding variables, adding these variables to the model did not affect the adjusted estimates (Wald test $p$ value of 0.6981 for GP or paediatrician visits and likelihood ratio chi-square (4 degrees of freedom): $3.1 ; p=0.54$ for hospitalisation for chronic conditions).

Table 2. Effectiveness of trivalent 2011/12 influenza vaccine against any type of influenza virus and influenza $A\left(\mathrm{H}_{3} \mathrm{~N}_{2}\right)$ virus in recruited influenza cases $(n=128)$ and test-negative controls $(n=69)$ targeted for vaccination, cycEVA study, Spain, week 52 (25-31 December) 2011-week 7 (13-19 February) 2012

\section{Genetic analysis of selected isolates}

Sequence analysis of the amplified $\mathrm{HA}_{1}$ genome fragment showed that out of 48 influenza $A$ virus strains studied, 31 clustered into the group represented by A/Stockholm/18/2011 defined by the V223l amino acid mutation (compared with the vaccine strain $A /$ Perth/16/2009). The remaining influenza $A$ viruses clustered into the group represented by $A$ / lowa/19/2010. Regarding influenza B virus, sequence analysis showed that the only virus analysed genetically in the study clustered into the Yamagata lineage, B/Bangladesh/3333/2007 genetic clade, which was not included in the seasonal vaccine.

\section{Discussion}

There are some noteworthy aspects of the current influenza season in Spain. Firstly, the epidemic peak was not reached until February 2012 [10]. Such a late epidemic peak was seen in only other two previous influenza seasons since 1996: in 2005/06 and 2006/07 $[11,12]$. Secondly, there has been a minimal contribution of the influenza $A\left(\mathrm{H}_{1} \mathrm{~N}_{1}\right)$ pdmog virus, which has been the predominant virus since the 2009 pandemic $[13,14]$.

Our influenza VE estimates in people in target groups for vaccination suggest a moderate effectiveness of the 2011/12 influenza vaccine against medically attended laboratory-confirmed influenza. The estimates were similar, whether against any type of influenza virus or $\mathrm{A}\left(\mathrm{H}_{3} \mathrm{~N}_{2}\right)$ virus. However, these are preliminary results that should be interpreted with caution, taking into consideration the small sample size.

Several factors might have contributed to the moderate protective effect of the vaccine. Firstly, there has been a limited match between the circulating $\mathrm{A}\left(\mathrm{H}_{3} \mathrm{~N}_{2}\right)$ strains compared with the vaccine strain in the northern hemisphere [15]. The majority of circulating $A\left(\mathrm{H}_{3} \mathrm{~N}_{2}\right)$ viruses in Spain were clustered into the group represented by A/Stockholm/18/2011, which was reported to be antigenically and genetically distinct from the vaccine virus A/Perth/16/2009 [16,17]. However, our VE estimates are consistent with those in studies carried out in previous years with a predominant circulation of seasonal influenza $A\left(\mathrm{H}_{3} \mathrm{~N}_{2}\right)$ virus. In these studies, influenza VE ranged from $10 \%$ to $68 \%$, depending on the degree of antigenic match [18-22]. It is important to note that although the effectiveness of the influenza vaccine is often less pronounced during seasons with antigenic mismatch between vaccine and circulation strains [23], in some influenza seasons antigenic changes occurred without resulting in any apparent loss of vaccine effectiveness [24].

Secondly, preliminary analysis in the cycEVA study would suggest a decrease of the influenza VE estimates with time since vaccination (data not shown). The median delay between the date of vaccination until the date of onset of symptoms was 106 days in cases versus 88 days in controls ( $p<0.004)$.

Taking into account several hypotheses that could explain this finding, we cannot exclude the possibility that this preliminary result could be related either to increasing circulation of the drifted strain in the epidemic peak or to potentially waning immunity in the months following vaccination. However, a bigger sample size is needed to investigate more fully the influenza VE during this atypical season. In addition, serological studies could help by investigating the seroprotection level in the studied population.

It is important to note that the population targeted for vaccination includes individuals vaccinated in successive influenza seasons, resulting in a more homogenous group in terms of potential confounding factors. In fact, in our study we found no differences in healthseeking behaviour or hospitalisation for chronic conditions in the previous year among cases and controls.

One limitation of our study was that the influenza vaccination coverage in the test-negative controls aged more than 64 years was higher than that in people of this age group in the GP and paediatricians' catchment area $(70 \%$ vs $56 \%)$. That is why we cannot extrapolate our VE estimates based on a population attended by GPs to all elderly people [5]. Another limitation is related to possible selection bias since swabbing was 
recommended for all older than 64 years old ILI patients and not for those targeted for vaccination.

This is the second season in which the cycEVA study has allowed early estimates of influenza VE in Spain to be obtained. In 2010/11, intraseasonal and end-season estimates were similar $[4,25]$, supporting the feasibility of generating and disseminating preliminary influenza VE estimates while virus circulation is still ongoing. The results presented here provide important information that will help to guide national authorities and policymakers in their recommendations for influenza vaccination. It would be helpful to remind clinicians of the importance of antiviral treatment for patients with severe influenza, while more evidence is gathered to support reconsideration of the timing of the influenza vaccination campaign every season.

In conclusion, these preliminary results suggest a moderate protective effect of the seasonal 2011/12 vaccine in preventing medically attended laboratory-confirmed influenza in the target groups for vaccination, during a season characterised by a late epidemic and a limited match between vaccine and circulating influenza strains. However, finding a protective value of the vaccine among those targeted for vaccination reinforces the importance of official recommendations for annual influenza vaccination.

\section{Acknowledgements}

We are grateful to sentinel GPs, paediatricians and virologists participating in the cycEVA study, as well as to all professionals participating in the Spanish Influenza Surveillance System. We thank Isabel Pachón y Aurora Limia (Coordinating Centre for Health Alerts and Emergencies within the Spanish Ministry of Health and Social Policy) for the information provided on influenza vaccination. We also thank the EpiConcept team for their fruitful discussions and comments on the cycEVA study. This work was supported by the ECDC through the I-MOVE project and by the Carlos III Institute of Health (Influenza A( $\left.\mathrm{H}_{1} \mathrm{~N}_{1}\right)$ pdmog Programme (GRog/0017)).

\section{References}

1. Valenciano $M$, Ciancio $B$, Moren $A$, the influenza vaccine effectiveness working group. First steps in the design of a system to monitor vaccine effectiveness during seasonal and pandemic influenza in EU/EEA Member States. Euro Surveill. 2008;13(43):pii=19015. Available from: http://www. eurosurveillance.org/ViewArticle.aspx?Articleld=19015

2. World Health Organization (WHO). Recommended viruses for influenza vaccines for use in the 2010-2011 northern hemisphere influenza season. Geneva: WHO; World Health Organization; 18 February 2010 (revised 5 March 2010). Available from: http://www.who.int/influenza/vaccines/virus/ recommendations/201002_Recommendation.pdf

3. Spanish Ministry of Health and Social Policy. Prevención de la gripe. Recomendaciones de vacunación antigripal. [Influenza prevention. Recommendations for influenza vaccination]. Spanish. Available from: http://www.msps.es/ciudadanos/ enfLesiones/enfTransmisibles/gripe/home.htm

4. Savulescu C, Jiménez-Jorge S, de Mateo S, Ledesma J, Pozo F, Casas l, et al. Effectiveness of the 2010/11 seasonal trivalent influenza vaccine in Spain: preliminary results of a case-control study. Euro Surveill. 2011;16(11):pii=19820. Available from: http://www.eurosurveillance.org/ViewArticle. aspx?Articleld $=19820$
5. Savulescu C, Valenciano M, de Mateo S, Larrauri A, the cycEVA Study Team. Estimating the influenza vaccine effectiveness in elderly on a yearly basis using the Spanish influenza surveillance network--pilot case-control studies using different control groups, 2008-2009 season, Spain. Vaccine. 2010;28(16):2903-7.

6. Savulescu C, Jiménez-Jorge S, de Mateo S, Pozo F, Casas I, Breña PP, et al. Using surveillance data to estimate pandemic vaccine effectiveness against laboratory confirmed influenza $A\left(\mathrm{H}_{1} \mathrm{~N}_{1}\right) 2009$ infection: two case-control studies, Spain, season 2009-2010. BMC Public Health. 2011;11:899.

7. Jiménez-Jorge S, Savulescu C, Pozo F, De Mateo S, Casas I, Ledesma J, et al. Effectiveness of the 2010-11 seasonal trivalent influenza vaccine in Spain: cycEVA study. Vaccine. Forthcoming.

8. European Commission. Commission Decision of 30 April 2009 amending Decision 2002/253/EC laying down case definitions for reporting communicable diseases to the Community network under Decision No 2119/98/EC of the European Parliament and of the Council. Luxembourg: Publications Office of the European Union. 1.5.2009:L 110/58. Available from: http://eur-lex.europa.eu/LexUriServ/LexUriServ.do?uri= OJ:L:2009:110:0058:0059:EN:PDF

9. Rothman KJ, Greenland S, Lash TL, editors. Modern epidemiology, 3rd ed. Philadelphia: Lippincott-Raven. 2008 Validity in epidemiologic studies. p. 128-47.

10. Instituto de Salud Carlos III. National Centre of Epidemiology. La actividad gripal desciende en España tras alcanzar el pico de la onda epidémica en la semana 07/2012. Semana 08/2012 (20 - 26 de febrero 2012). [Influenza activity is decreasing in Spain after the epidemic wave peaked in week 07/2012. Week 08/2012 (20-26 February 2012)]. Spanish. Available from: http://www.isciii.es/ISCIII/es/contenidos/fd-servicioscientifico-tecnicos/fd-vigilancias-alertas/fd-enfermedades/fdgripe/fd-informes-semanales-vigilancia-gripe/grno812.pdf

11. Instituto de Salud Carlos III. National Centre of Epidemiology. Informe anual de gripe de la temporada 2005-2006. Vigilancia de la gripe en España. Sistema Centinela. [Annual influenza report. Season 2005-2006. Influenza surveillance in Spain. Sentinel System]. Spanish. Available from: http://vgripe.isciii. es/gripe/documentos/20052006/InformesAnuales/Gripe0506. pdf

12. Instituto de Salud Carlos III. National Centre of Epidemiology. Informe anual de gripe de la temporada 2006-2007. Vigilancia de la Gripe en España. Sistema centinela. [Annual influenza report, Season 2006-2007. Influenza surveillance in Spain. Sentinel System]. Spanish. Available from: http://vgripe.isciii. es/gripe/documentos/20062007/InformesAnuales/Informe Temporada_06-07.pdf

13. Instituto de Salud Carlos III. National Centre of Epidemiology. Informe anual de gripe - Evolución de la gripe pandémica por $\mathrm{AnH}_{1} \mathrm{~N}_{1}$ (Desde la semana 20/2009 hasta la semana 20/2010). Sistema de Vigilancia de la Gripe en España. [Annual influenza report. Evolution of pandemic influenza by $A_{(}\left(\mathrm{H}_{1} \mathrm{~N}_{1}\right) 2009$ (from week 20/2009 to week 20/2010). Spanish Influenza Surveillance System]. Spanish. Available from: http://vgripe. isciii.es/gripe/documentos/20092010/InformesAnuales/ Informe_anual_temporada_2009-2010.pdf

14. Instituto de Salud Carlos III. National Centre of Epidemiology. Informe anual de gripe de la temporada 2010-2011 (Desde la semana $40 / 2010$ hasta la semana 20/2011). Sistema de Vigilancia de la Gripe en España. [Annual influenza report. Season 2010-2011. Spanish Influenza Surveillance System]. Spanish. Available from: http://vgripe.isciii.es/gripe/ documentos/20102011/InformesAnuales/Informe_GRIPE_ Temporada_2010-11_07092011.pdf

15. World Health Organization (WHO). Recommended composition of influenza virus vaccines for use in the 2012-2013 northern hemisphere influenza season. Geneva: WHO; February 2012. Available from: http://www.who.int/influenza/vaccines/virus/ recommendations/201202_recommendation.pdf

16. World Health Organization (WHO). Recommended composition of influenza virus vaccines for use in the 2011-2012 northern hemisphere influenza season. Geneva: WHO. [Accessed 22 Mar 2012]. Available from: http://www.who.int/influenza/vaccines/ virus/recommendations/recommendations_2011_12north/en/

17. European Centre for Disease Control and Prevention (ECDC). Community Network of Reference Laboratories (CNRL) for Human Influenza in Europe. Influenza virus characterisation. Summary Europe, February 2012. Stockholm: ECDC; Feb 2012. Available from: http://ecdc.europa.eu/en/publications/ Publications/1203_TED_CNRL_report_Feb2011.pdf

18. Fleming DM, Andrews NJ, Ellis JS, Bermingham A, Sebastianpillai $P$, Elliot AJ, et al. Estimating influenza vaccine effectiveness using routinely collected laboratory data. J Epidemiol Community Health. 2010;64(12):1062-7. 
19. Fielding JE, Grant KA, Papadakis G, Kelly HA. Estimation of type- and subtype-specific influenza vaccine effectiveness in Victoria, Australia using a test negative case control method, 2007-2008. BMC Infect.Dis. 2011;11:170.

20. Skowronski DM, De Serres G, Dickinson J, Petric M, Mak A, Fonseca K, et al. Component-specific effectiveness of trivalent influenza vaccine as monitored through a sentinel surveillance network in Canada, 2006-2007. J Infect.Dis. 2009;199(2):168-79.

21. Kelly H, Carville K, Grant K, Jacoby P, Tran T, Barr I. Estimation of influenza vaccine effectiveness from routine surveillance data. PLoS One. 2009;4(3):e5079.

22. Belongia EA, Kieke BA, Donahue JG, Greenlee RT, Balish $A$, Foust $A$, et al. Effectiveness of inactivated influenza vaccines varied substantially with antigenic match from the 2004-2005 season to the 2006-2007 season. J Infect Dis. 2009;199(2):159-67.

23. Carrat F, Flahault A. Influenza vaccine: the challenge of antigenic drift. Vaccine. 2007;25(39-40):6852-62.

24. Centers for Disease Control and Prevention (CDC). Interim within-season estimate of the effectiveness of trivalent inactivated influenza vaccine--Marshfield, Wisconsin, 2007-08 influenza season. MMWR Morb Mortal Wkly Rep. 2008;57(15):393-8.

25. Kissling E, Valenciano M, Cohen JM, Oroszi B, Barret AS, Rizzo C, et al. I-MOVE multi-centre case control study 201011: overall and stratified estimates of influenza vaccine effectiveness in Europe. PLoS One. 2011;6(11):e27622. 